\title{
First report of the unique expression of RECAF (receptor for alfa feto-protein) in adult B-NHL/CLL patients
}

\author{
Hebatallah Adel Sedky ${ }^{1}$, Soha Raouf Youssef ${ }^{1}$, Doaa Ahmad Gamal ${ }^{1}$, Heba Fawzy Houssein ${ }^{1}$, \\ Walaa Ali Elsalakawy ${ }^{2}$ \\ ${ }^{1}$ Clinical Pathology Department, ${ }^{2}$ Clinical Hematology and Bone Marrow Transplant Unit, Internal Medicine Department, Ain \\ Shams University, Faculty of Medicine, Cairo, Egypt
}

p-ISSN 2287-979X / e-ISSN 2288-0011 https://doi.org/10.5045/br.2020.2020070 Blood Res 2020;55:253-261.

Received on April 7, 2020

Revised on October 3, 2020

Accepted on November 12, 2020

\author{
Correspondence to \\ Walaa Ali Elsalakawy, M.D. \\ Clinical Hematology and Bone Marrow \\ Transplant Unit, Internal Medicine \\ Department, Ain Shams University, \\ Faculty of Medicine, Cairo 11241, Egypt \\ E-mail: drwalaa2010@gmail.com \\ (C) 2020 Korean Society of Hematology
}

\begin{abstract}
Background
Lymphoproliferative disorders (LPDs) are a heterogeneous group of diseases characterized by an uncontrolled production of monoclonal lymphocytes. RECAF is the receptor for alpha-fetoprotein, which is re-expressed on malignant cells, thus serving as a broad-spectrum tumor marker.
\end{abstract}

\section{Methods}

The current study is a retrospective study carried out on 200 archival bone marrow trephine biopsy specimens [60 normal control (NC), 38 pathological control (PC) and 102 lymphoproliferative diseases (LPD) specimens]. RECAF expression was assessed using immunohistochemistry.

\section{Results}

The percentage of cells that are positive for RECAF was significantly higher in the LPD group than in the $\mathrm{NC}$ group $(P=0.007)$, while there was no significant difference between non-Hodgkin lymphoma (NHL) patients and $\mathrm{PC}$ regarding the number of RECAF positive cells $(P=0.1)$. RECAF showed a unique expression pattern among the different subtypes of LPD. None of the hairy cell leukemia ( $\mathrm{HCL}$ ) expressed RECAF, while the highest percentage was seen in follicular lymphoma (FL) and diffuse large B cell lymphoma (DLBCL) $(P=0.001)$. Compared to routine histopathology, RECAF was more sensitive in detecting bone marrow $(\mathrm{BM})$ infiltration in $\mathrm{FL}$, mantle cell lymphoma $(\mathrm{MCL})$, and $\mathrm{DLBCL}(P=0.01)$.

\section{Conclusion}

RECAF is significantly expressed in the BM of NHL/chronic lymphocytic leukemia (CLL) patients. RECAF shows a unique expression pattern among the different subtypes of LPD. Furthermore, RECAF may help to detect bone marrow infiltration in lymphoma cells. This may help in the diagnosis, follow-up, and targeting of LPD.

Key Words Lymphoma, RECAF, Hairy cell leukemia, Chronic lymphocytic leukemia, Diffuse large B cell lymphoma, Follicular lymphoma

\section{INTRODUCTION}

According to the current world health organization (WHO) classification, mature B-cell neoplasms involve a myriad of LPDs, whose presentation and progression vary from indolent to aggressive. Several imaging studies and laboratory tests are usually performed prior to initiation of therapy for staging and prognosis purposes [1].

For the laboratory testing, the cornerstone remains the lymph node biopsy, since more than two-thirds of lymphoma cases present with peripheral lymphadenopathy [2]. Equally important is determining the bone marrow involvement because it is the most common site of extra-nodal involvement in lymphoid malignancies and represents a disseminated disease. In some cases, it is the only accessible site or, in rare situations, the only site of involvement [2]. Since radiological investigations cannot fully assess the degree or pattern of involvement, confirmed infiltration is only possible via pathological examination. However, in the cases where bone 
marrow morphology is inconclusive, due to focal infiltration or an increased number of reactive cells, immunohistochemistry is the only tool that can be used for a definite diagnosis [2].

RECAF is a receptor present on the surface of fetal cells and in the cytoplasm. It binds and internalizes the circulating major fetal serum protein, alpha fetal protein (AFP), which is synthesized in the fetus by the yolk sac and liver, and then declines after birth, being absent in adults $[3,4]$. While the AFP is a well-known tumor marker in hepatic and testicular carcinoma cases, RECAF is a newly emerging broad-spectrum tumor marker [5]. AFP in prenatal life, like albumin in adults, transports molecules intracellularly via its receptor $[6,7]$. The uptake of AFP and, hence, the expression of its receptor (RECAF) is closely related to the degree of cell differentiation. It is maximally expressed in immature undifferentiated fetal cells and tissues [5].

In vitro and in vivo studies have shown that malignant cells regain the ability to uptake AFP via its receptor (RECAF). RECAF expression was identified in several malignant cell lines, such as breast, colon, lung, and rectal carcinoma cells, but was absent from normal adult tissues [8-13]. RECAF is considered an oncofetal antigen with cancer diagnosis, screening, and follow-up potential [5].

To our knowledge, the expression of RECAF in patients with non-Hodgkin lymphoma has not yet been evaluated. This study aimed to explore the expression of RECAF in LPD patients and its possible correlations with clinical and laboratory parameters.

\section{MATERIALS AND METHODS}

The current study is a retrospective study carried out using 200 archival bone marrow trephine biopsy specimens. They were subdivided into three major groups.

\section{Group (I) or normal control (NC)}

This group included 60 archival BM trephine biopsies free of malignant diseases. These patients have done bone marrow biopsies as a part of their work-up for evaluating thrombocytopenia, hypersplenism, anemia of chronic disease, or aplastic anemia. All of them were proved to have no malignant diseases and reached a final benign final diagnosis.

\section{Group (II) or pathological control (PC)}

This group included 38 cases (8 CML cases, 4 cases of yolk sac tumors, 8 cases of neuroblastoma, 9 ALL cases, and 9 multiple myeloma cases).

\section{Group (III) or LPD patients}

This group included 102 archival bone marrow trephine biopsies of B-LPD patients (44 DLBCL cases, 22 FL cases, 10 MCL cases, 14 CLL cases, and 12 HCL cases).

Informed verbal consent was obtained from all subjects at the time of initial sampling. All procedures performed in our study were performed in accordance with the ethical standards of the institutional and national research committee. The study procedures respected the ethical standards in the Declaration of Helsinki and its later amendments.

\section{Diagnostic workup of B-LPD}

Data retrieved from the medical files of patients included:

I. Clinical data, including full clinical history, physical examination, staging (according to the Ann Arbor staging system), and allocation into risk groups (the International Prognostic Factors Project for NHL);

II. Laboratory data, including complete blood count (CBC) (MaxM, Coulter, Boston, MA, USA), the differential white blood cell count, chemical profile (liver and kidney function tests, LDH, uric acid) (Synchron 7X, Beckman Coulter, Brea, CA, USA), cerebro-spinal fluid (CSF) analysis (if needed), lymph node histopathological examination and immunohistochemical staining, histopathological examination of bone marrow aspiration and trephine biopsies, and flow cytometry immunophenotype to establish clonality (Epics II, Beckman Coulter, Brea, CA, USA);

III. Radiological data, including chest $\mathrm{X}$-ray and/or Computed tomography (CT), abdomen/pelvis ultrasound, PET scan, and magnetic resonance imaging (MRI), when indicated;

IV. Detection of bone marrow infiltration was confirmed in all cases using immunohistochemistry after an initial histopathological examination of bone marrow samples by performing at least CD20/CD3 analysis and evidence of clonality (kappa/lambda).

\section{Detection of RECAF using immunohistochemistry (IHC)}

Tissue cuts, 4-6- $\mu \mathrm{m}$ thick, were obtained from blocks of archival formalin-fixed/paraffin-embedded BM trephine biopsies and applied on positively charged slides.

Deparaffinization was performed through passage in $\mathrm{xy}^{-}$ lene $(\times 3,5 \mathrm{~min}$ each). Rehydration of the sections was done using a graded alcohol series $(\times 2,10 \mathrm{~min}$ each in $100 \%$, followed by $95 \%$ ethanol), followed by an agitated wash in deionized water for $1 \mathrm{~min}$.

Immunohistochemical staining was performed using the avidin-biotin immuno-peroxidase technique. A peroxidase blocker $(0.3 \%$ hydrogen peroxide and $0.1 \%$ sodium azide) was applied for 10-20 min on the tissue area encircled by a diamond pen to inhibit the action of endogenous peroxidase. Incubation overnight at $2-8^{\circ} \mathrm{C}$ in a humidified chamber with the primary antibody (mouse monoclonal anti-AFP receptor) (Santa Cruz, CA, USA) was followed by incubation for 30 min each with a secondary biotin-conjugated antibody, and then streptavidin-peroxidase conjugate. DAB (freshly prepared) was applied for 6-12 min and washed twice in phosphate buffer saline (PBS) $7 \%$ after each step.

Counterstaining was performed in hematoxylin for a maximum of 30-60 s. Dehydration (in increasing grades of ethanol) was followed by cleaning with xylene, and mounting.

Controls were used for each run (for validity and quality): positive from a placental tissue and negative, in which the 
primary antibody was replaced by non-immune serum.

\section{Interpretation of results}

At least 100-200 cells per smear were counted by two experienced hemato-pathologists to evaluate the number and percentage of RECAF-positive cells.

\section{Statistical methods}

Data were analyzed statistically using SPSS version 13 . Central tendencies and dispersion [mean $(\bar{x})$ /standard deviation (SD) in parametric data or median/Interquartile (IQ) in non-parametric data] were calculated.

For probability, the chi-square test $\left(\mathrm{X}^{2}\right)$, Wilcoxon rank sum test, Fisher's exact test, and Student's t-test for independent samples were performed. Statistical correlations between data were calculated according to the Ranked Spearman correlation test.

The diagnostic validity test of RECAF, including the cut-off level, sensitivity, specificity, and efficacy were determined

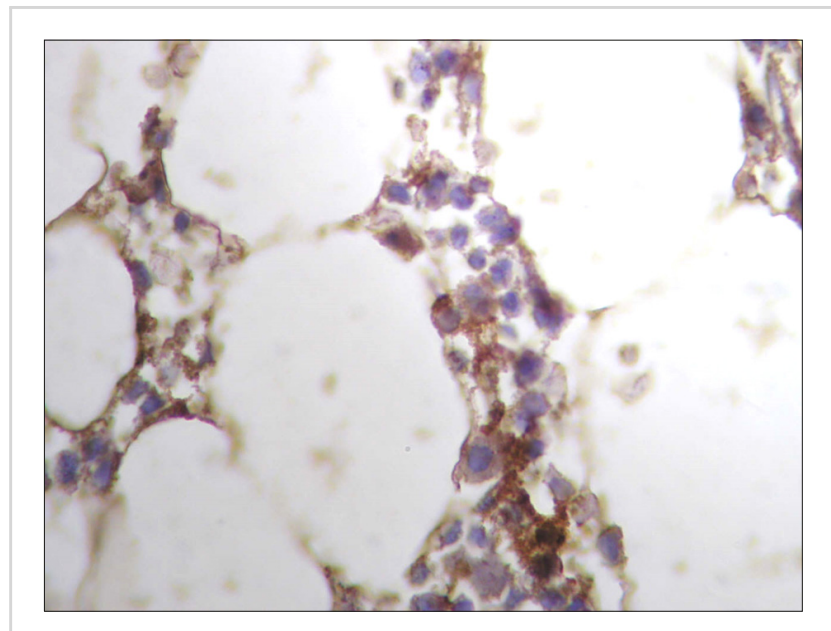

Fig. 1. Diffuse RECAF positive reaction in the majority of cells in DLBCL.

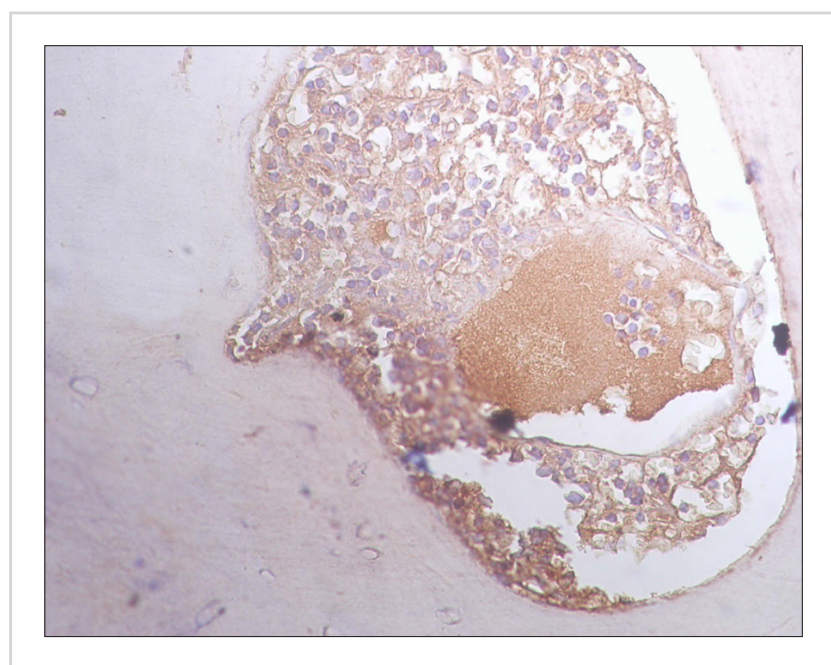

Fig. 2. Diffuse RECAF positivity in DLBCL. using receiver operating characteristic curve (ROC curve) analysis.

The $P$-values indicating statistical significance and a high statistical significance were lower than 0.05 and 0.01 , respectively.

\section{RESULTS}

See Fig. 1-19.

\section{Clinical characteristics of the studied groups}

The study included 200 archival bone marrow trephine biopsies. Subjects were subdivided into three major groups: normal controls (group I, $\mathrm{N}=60$ ), pathological controls (group II, $\mathrm{N}=38$ ), and LPD cases (group III, $\mathrm{N}=102$ ). Clinical and laboratory findings of the studied groups are presented in Table 1, while the descriptive data and staging of group III are presented in Table 2.

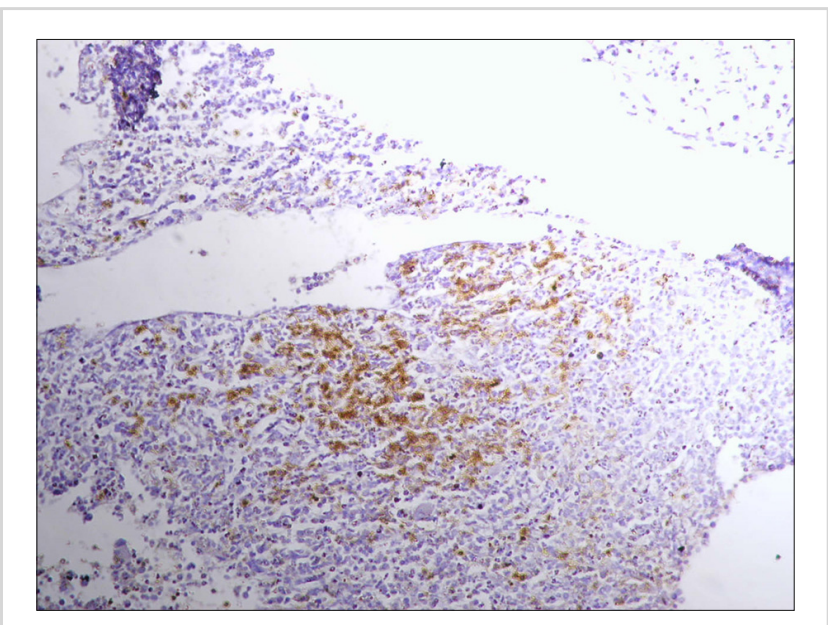

Fig. 3. Collections of RECAF-positive cells in DLBCL.

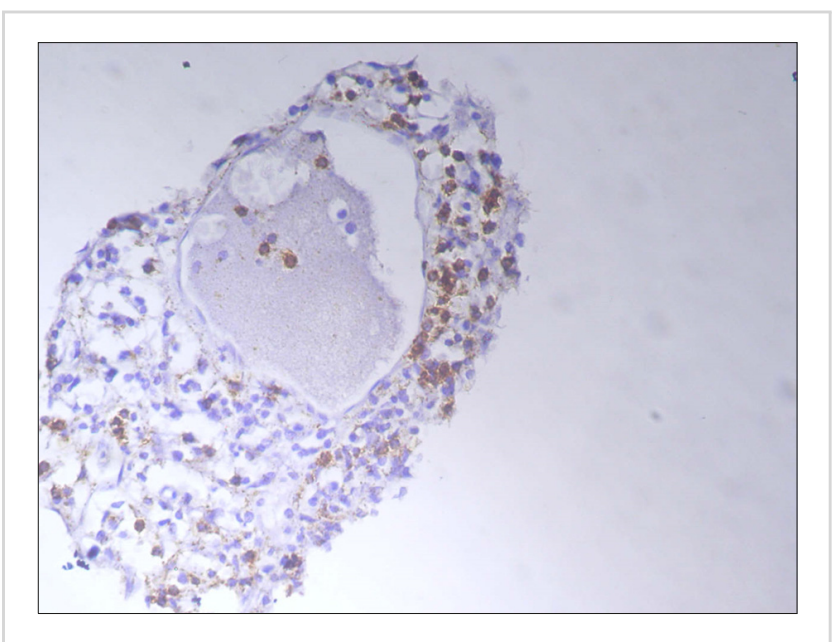

Fig. 4. Sporadic RECAF-positive cells in DLBCL. 


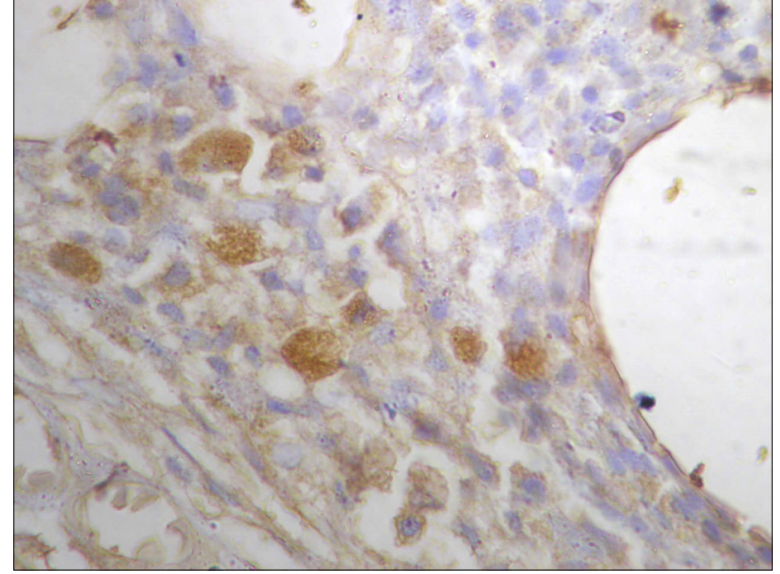

Fig. 5. Many and deeply stained RECAF-positive cells in DLBCL.

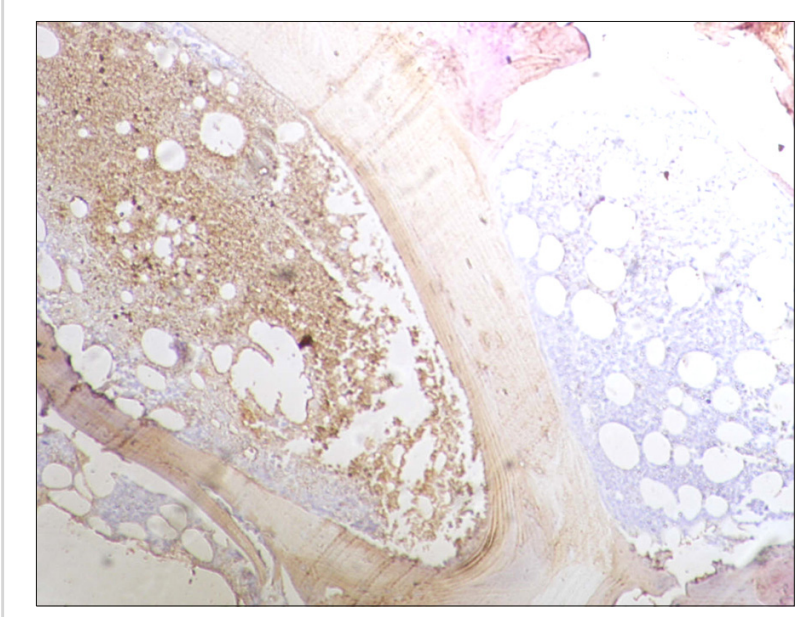

Fig. 6. RECAF-positive follicle (on the left) and a negative follicle (right) in the FL.

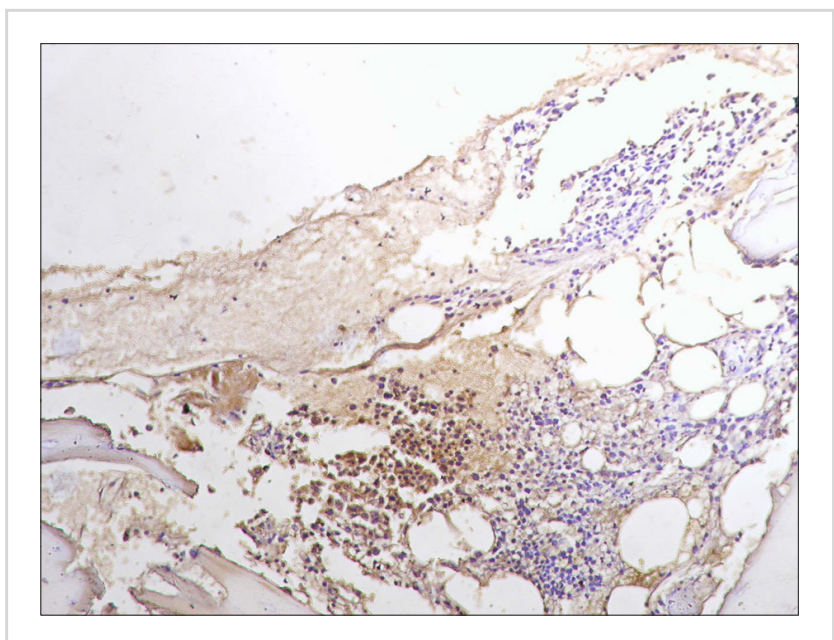

Fig. 7. A collection of RECAF-positive cells surrounded by negative cells in $\mathrm{FL}$.

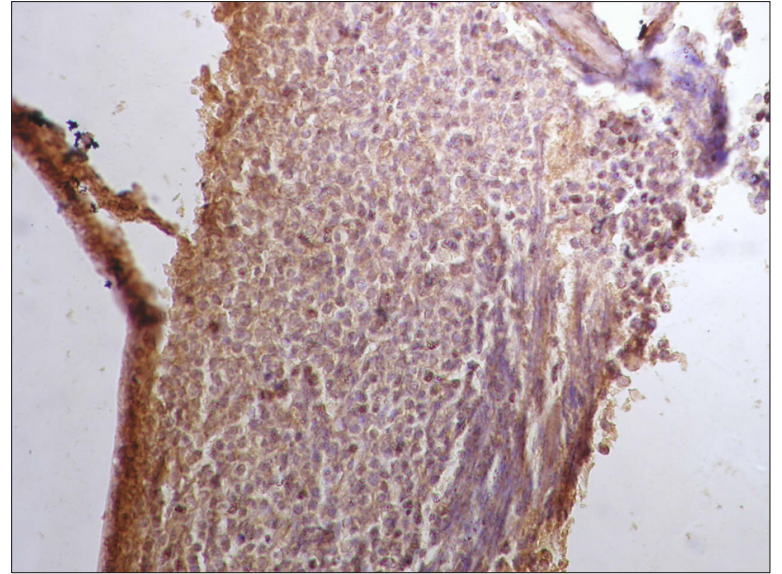

Fig. 8. Diffuse RECAF positivity in FL.

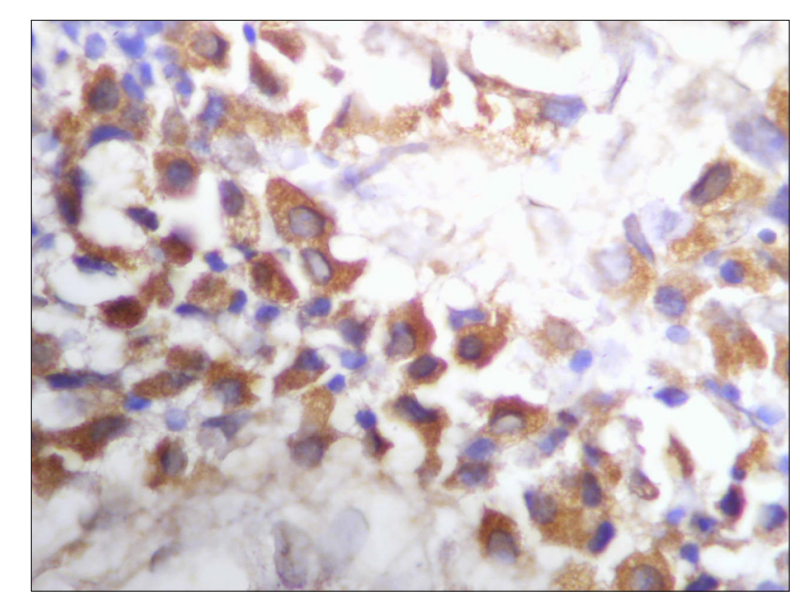

Fig. 9. Many and deeply stained RECAF-positive cells in MCL.

Expression of RECAF using Immunohistochemistry (IHC), see Table 1 \& 3

Five of the 60 normal controls (8\%) showed cells that were positive for RECAF expression using IHC. The percentage of RECAF-positive cells in the NC group ranged from $0 \%$ to $12 \%$, with a median of $0 \%$ and an IQ range of $6 \%$.

The percentage of positive cells in the PC group ranged from $0 \%$ to $40 \%$ with a median of $6 \%$ and an IQ range of $20 \%$ (32-40\% in ALL and $12-15 \%$ in neuroblastoma, but was negative in CML, multiple myeloma, and yolk sac tumors).

The percentage of RECAF-positive cells in DLBCL, FL, MCL, and CLL patients ranged from $0 \%$ to $80 \%, 0 \%$ to $90 \%, 0 \%$ to $65 \%$, and $0 \%$ to $40 \%$, with a median of $3 \%$, $22 \%, 7 \%$, and $10 \%$, and an IQ range of $40 \%, 45 \%, 32.5 \%$, and $20 \%$, respectively. Meanwhile, all HCL cases were negative for RECAF.

The percentage of RECAF-positive cells was significantly higher in PC and LPD groups compared to the normal control 


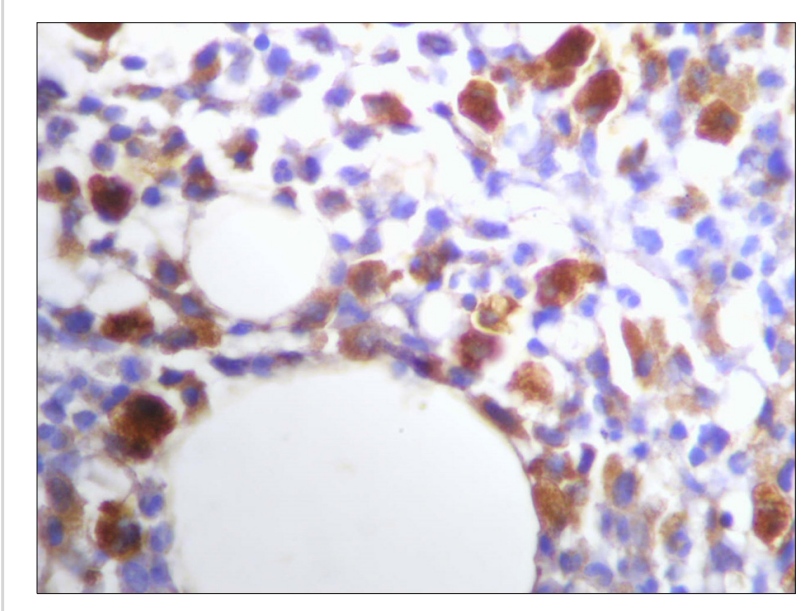

Fig. 10. Many and deeply stained RECAF-positive cells in MCL.

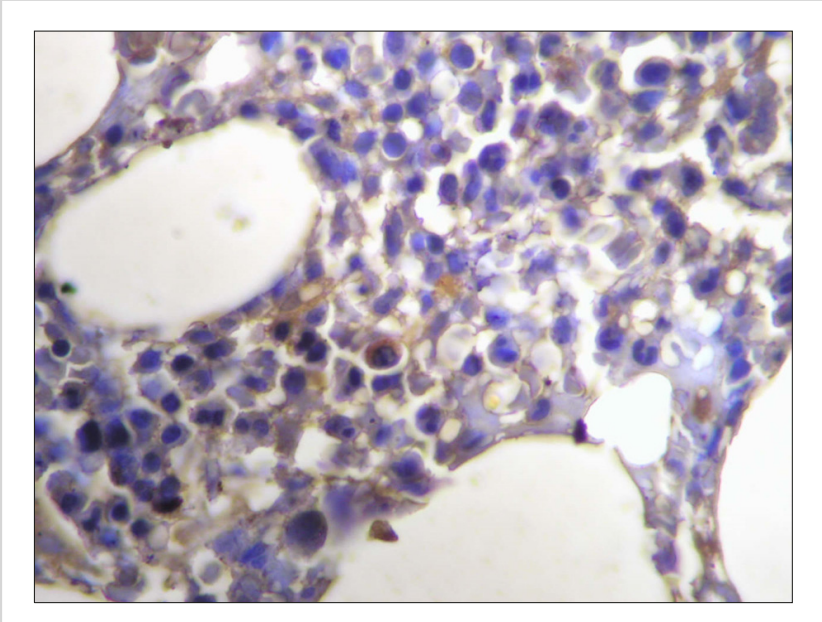

Fig. 11. Scattered RECAF-positive cells in CLL.

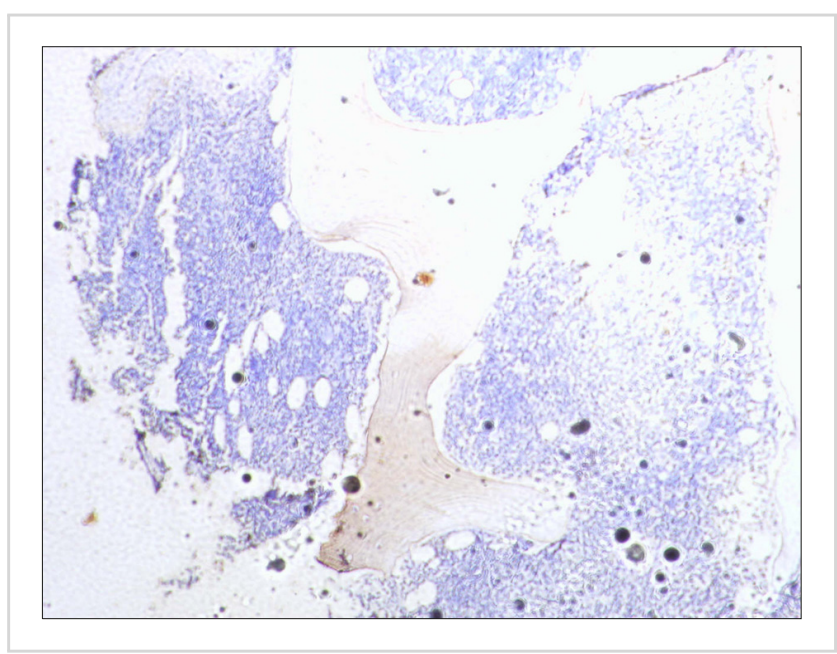

Fig. 12. HCL negative for RECAF.

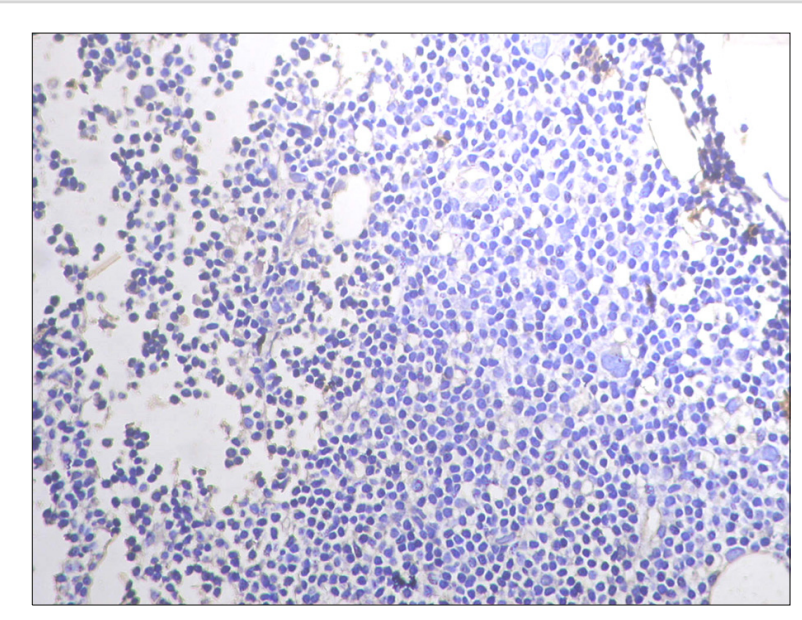

Fig. 13. HCL negative for RECAF.

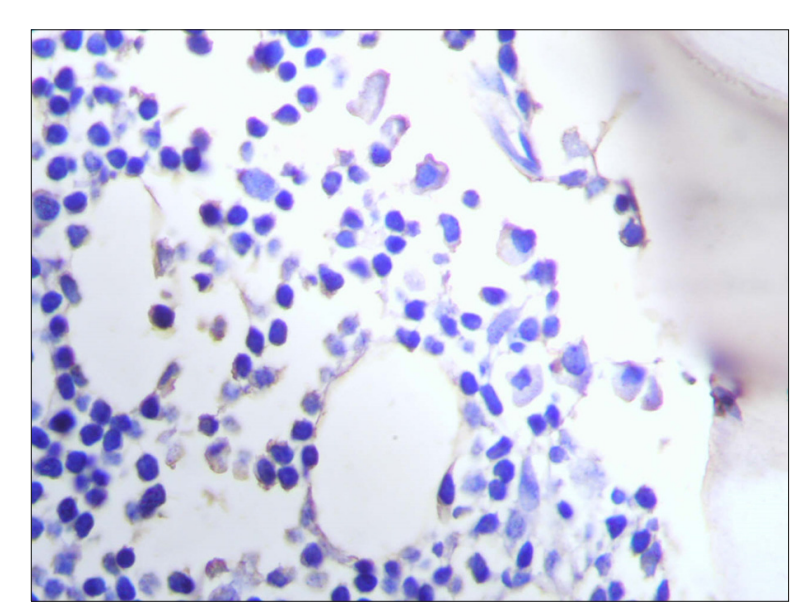

Fig. 14. Sporadic RECAF-positive cells in neuroblastoma.

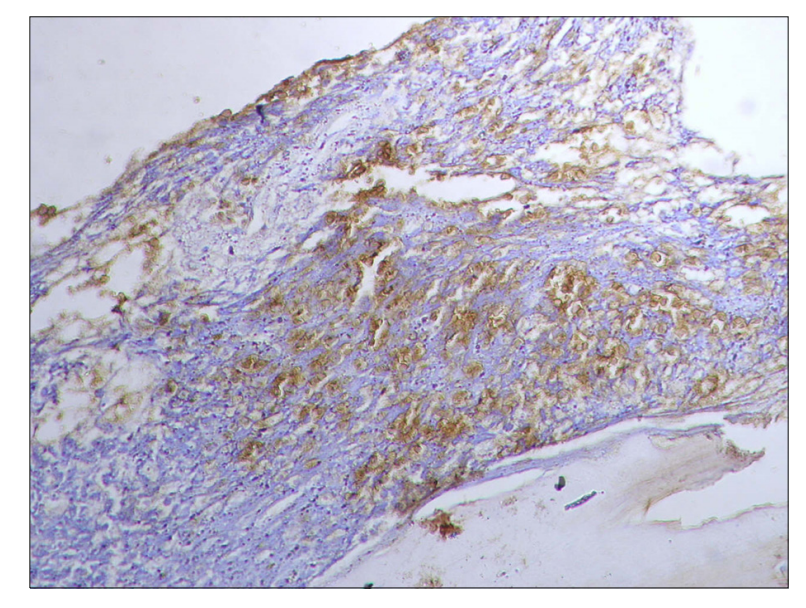

Fig. 15. Collections of RECAF-positive cells in ALL. 


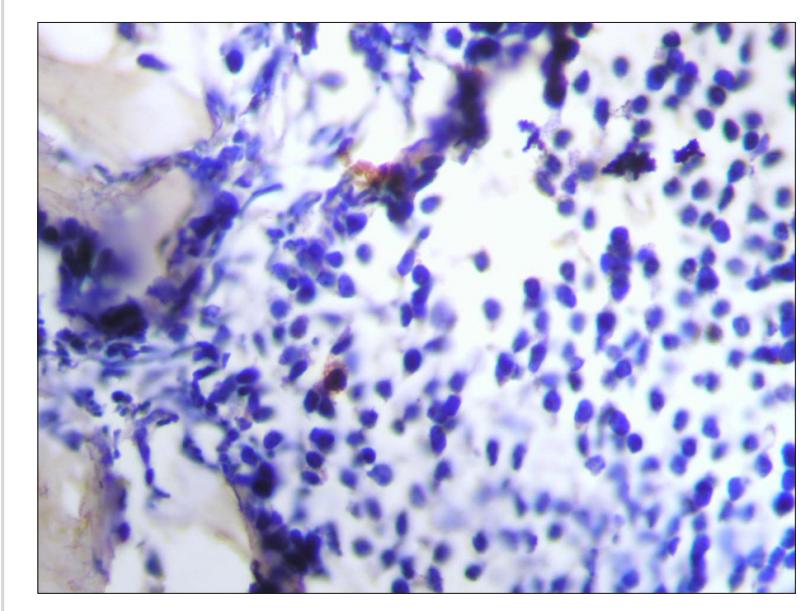

Fig. 16. Few RECAF-positive cells in Multiple Myeloma.

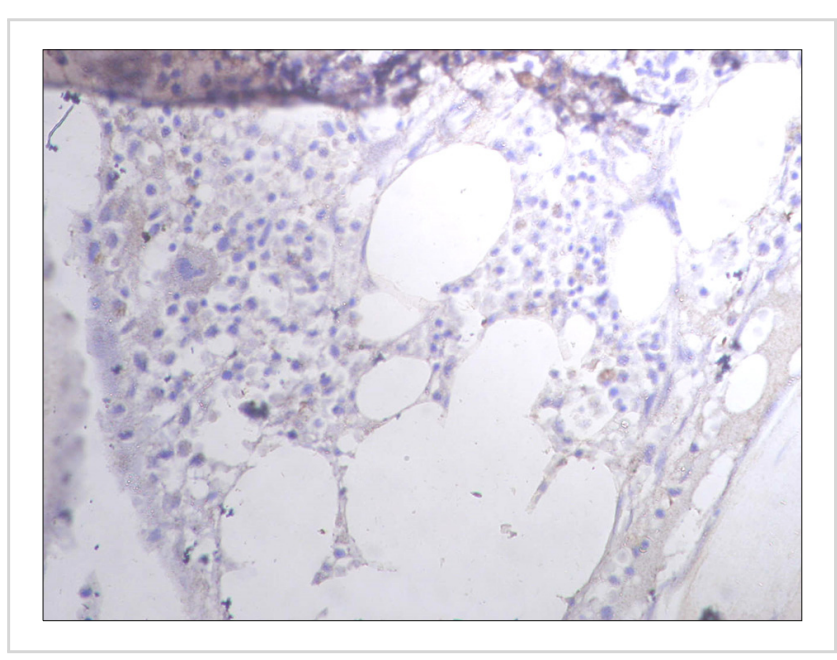

Fig. 17. Sporadic RECAF-positive cells in neuroblastoma.

group ( $P=0.02$ and 0.007 respectively). There was no significant difference between NHL patients and the PC group regarding the number of positive cells $(P=0.1)$.

\section{Comparison between LPD subgroups regarding RECAF expression}

The percentage of RECAF-positive cells was significantly higher in FL, MCL, DLBCL, and CLL, than in HCL $(P=0.001)$, with the highest percentage observed in FL and DLBCL $(P=0.001)$ (Table 3).

\section{Assessment of BM infiltration via routine histopathology}

None of the patients in Group I (normal control) showed $\mathrm{BM}$ infiltration by malignant diseases. In the pathological control group (group II), all samples were negative for BM infiltration via routine histopathological examination, except for CML, MM, and ALL cases.

Fifty-two of the 102 LPD patients (51\%) had BM infiltration, which was detected via routine histopathological examination. These were 12/44 (27.3\%) DLBCL, 12/22

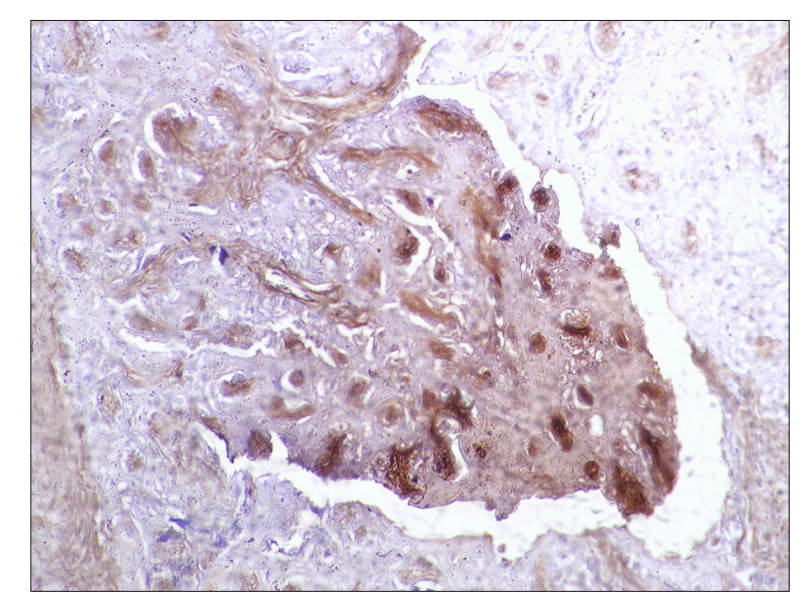

Fig. 18. Placental tissue stained with RECAF (positive control).

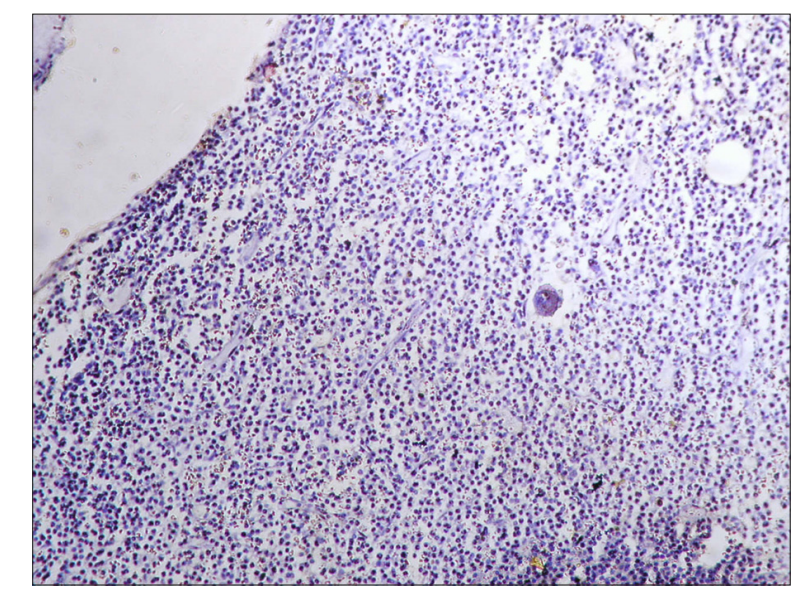

Fig. 19. Normal control negative for RECAF.

(54.5\%) FL, 2/10 (20\%) MCL, all 14 CLL, and 12 HCL patients (Table 2).

Cut off percentages of RECAF-positive cells for which BM infiltration was identified

ROC curve analysis of the percentage of RECAF-positive cells in the smears revealed various cut-off values above which the cases were designated as positive for RECAF expression. Accordingly, BM infiltration by RECAF was identified in FL, MCL, DLBCL, and CLL patients at cut-off values of $6 \%, 5 \%, 10 \%$, and $15 \%$, respectively (Table 4 ).

Role of RECAF expression in the detection of BM infiltration versus routine $\mathrm{IHC}$

Among the PC group, although IHC was more sensitive than routine histopathology for the detection of BM infiltration, the difference was not statistically significant $(P=0.9)$.

Regarding CLL and HCL, the detection of BM infiltration was significantly higher using histopathology 26/26 (100\%) compared to RECAF 6/26 (23\%) $(P=0.001)$. In FL, MCL, 
and DLBCL, the detection of RECAF using IHC was more sensitive than routine histopathology for the detection of $\mathrm{BM}$ infiltration $(P=0.01)$.

\section{DISCUSSION}

Bone marrow examination in lymphoproliferative diseases

\begin{tabular}{|c|c|c|c|}
\hline Parameter & NC & PC & $\mathrm{NHL}$ \\
\hline Age, yr (mean $\pm S D)$ & $37 \pm 7.8$ & $24.2 \pm 7.3$ & $48 \pm 11.2$ \\
\hline Gender, male/female & $32 / 28$ & $21 / 17$ & $47 / 55$ \\
\hline $\mathrm{Hb}, \mathrm{g} / \mathrm{dL}($ mean $\pm \mathrm{SD})$ & $11.5 \pm 1.4$ & $11.5 \pm 2.2$ & $11.9 \pm 1.1$ \\
\hline $\begin{array}{l}\text { Platelets, cells } \times 10^{3} / \mu \mathrm{L} \\
(\text { mean } \pm \mathrm{SD})\end{array}$ & $217 \pm 51.3$ & $216.8 \pm 68.8$ & $271.1 \pm 86.8$ \\
\hline $\begin{array}{l}\mathrm{LDH}, \mathrm{mg} / \mathrm{dL} \\
(\mathrm{mean} \pm \mathrm{SD})\end{array}$ & $292 \pm 37.7$ & $336 \pm 70.6$ & $540.4 \pm 176.7$ \\
\hline $\begin{array}{l}\text { Lymphocytes, cells } \times \\
10^{3} / \mu \mathrm{L} \text { (median and } \\
\text { IQ range) }\end{array}$ & $1.8(2.2)$ & $1.9(23.3)$ & $2.4(16.7)$ \\
\hline
\end{tabular}

Abbreviations: $\mathrm{Hb}$, hemoglobin; HSM, hepatosplenomegaly; LDH, lactate dehydrogenase; LNS, lymph nodes; NC, normal control; NHL, non-hodjken lymphoma; PC, pathological control; $\mathrm{SD}$, standard deviation. is essential for diagnosis, staging, and prognostic evaluation. Immunohistochemical studies help to reach a definite diagnosis via a variety of $\mathrm{B}$ cell or $\mathrm{T}$ cell lineage markers. RECAF is a receptor for alpha fetoprotein, that serves as a broad-spectrum tumor marker.

The current study is a retrospective study carried out using 200 archival bone marrow trephine biopsy specimens, including specimens from normal control (NC), pathological control (PC), and LPD patients. In our study, the number of RECAF-positive cells was significantly higher in LPD patients than in NC patients $(P=0.007)$. To our knowledge, this is the first study to investigate the expression of RECAF in NHL/CLL patients using IHC. We document for the first time that RECAF was significantly higher in LPD patients than in normal controls. This will open the door for further evaluation of a possible role of RECAF in the diagnosis, follow-up, detection of minimal residual disease, and detection of relapse in lymphoma patients. Further studies are ongoing at our university.

The uptake of AFP was first documented in fetal cells; it was observed in all three germ layers, ecto-, meso-, and endodermal tissues, whether obtained from human, bird, or mammal embryos [14-20]. Later studies showed the capability of muscle tumor cells to internalize exogenous AFP in rhabdomyosarcoma; later in 1984, another study showed

Table 2. Descriptive data of NHL/CLL cases subgroups included in the study.

\begin{tabular}{|c|c|c|c|c|c|}
\hline Parameter & DLBCL $(N=44)$ & $\mathrm{FL}(\mathrm{N}=22)$ & $\operatorname{MCL}(\mathrm{N}=10)$ & CLL $(N=14)$ & $\mathrm{HCL}(\mathrm{N}=12)$ \\
\hline Age, yr (mean $\pm S D)$ & $43.5 \pm 10.8$ & $50.6 \pm 11.5$ & $48 \pm 4.3$ & $55 \pm 8.8$ & $52 \pm 14.2$ \\
\hline Gender (male/female) & $26 / 18$ & $8 / 14$ & $8 / 2$ & $6 / 8$ & $6 / 6$ \\
\hline $\mathrm{Hb}, \mathrm{g} / \mathrm{dL}($ mean $\pm \mathrm{SD})$ & $12.1 \pm 1.2$ & $11.8 \pm 0.9$ & $11.8 \pm 0.8$ & $11.6 \pm 0.3$ & $10.2 \pm 1.4$ \\
\hline $\begin{array}{l}\text { Platelets, cells } \times 10^{3} / \mu \mathrm{L} \\
(\text { mean } \pm \text { SD })\end{array}$ & $313 \pm 76.6$ & $245.8 \pm 73.8$ & $225.6 \pm 51.7$ & $159.2 \pm 9.9$ & $106.5 \pm 20.3$ \\
\hline $\mathrm{LDH}, \mathrm{mg} / \mathrm{dL}($ mean $\pm \mathrm{SD})$ & $555.3 \pm 159.6$ & $613.8 \pm 148.1$ & $730 \pm 105.1$ & $434.7 \pm 146.9$ & $316.3 \pm 44.4$ \\
\hline $\begin{array}{l}\text { Lymphocyte count, } \\
\text { cells } \times 10^{3} / \mu \mathrm{L} \\
\text { (median and IQ range) }\end{array}$ & $2.2(2.5)$ & $2(2.4)$ & $2.6(2.4)$ & $19(22)$ & $2.2(2.5)$ \\
\hline B-symptoms, N (\%) & 18 (40.9) & $8(36.4)$ & $2(20)$ & 4 (28.6) & $8(66.7)$ \\
\hline LNS, N (\%) & $44(100)$ & $22(100)$ & $10(100)$ & $10(71.4)$ & $2(16.7)$ \\
\hline HSM, N (\%) & $20(45.5)$ & $10(45.5)$ & $2(20)$ & $8(57.1)$ & $10(83.3)$ \\
\hline \multicolumn{6}{|l|}{ Stage, N (\%) } \\
\hline Stage1 & $8(18.2)$ & $2(9.1)$ & $0(0)$ & $0(0)$ & $0(0)$ \\
\hline Stage 2 & $14(31.8)$ & $2(9.1)$ & $0(0)$ & $0(0)$ & $0(0)$ \\
\hline Stage 3 & 6 (13.6) & $4(18.2)$ & $4(40)$ & $0(0)$ & $0(0)$ \\
\hline Stage 4 & $16(36.4)$ & $14(63.6)$ & $6(60)$ & $14(100)$ & $12(100)$ \\
\hline $\begin{array}{l}\text { BM infiltration by } \\
\text { histopathology, } \mathrm{N}(\%)\end{array}$ & $12(27.3)$ & $12(54.5)$ & $2(20)$ & $14(100)$ & $12(100)$ \\
\hline
\end{tabular}

Abbreviations: $\mathrm{Hb}$, hemoglobin; HSM, hepatosplenomegaly; LDH, lactate dehydrogenase; LNS, lymph nodes; N, number; SD, standard deviation.

Table 3. Comparison between different B-NHL subgroups as regards percent of RECAF positive cases.

\begin{tabular}{lccccc}
\multicolumn{1}{c}{ Parameter } & DLBCL & FL & MCL & CLL & HCL \\
\hline RECAF+ve cases, N (\%) & $16 / 44(36.1)$ & $20 / 22(90.9)$ & $8 / 10(80)$ & $6 / 14(42.8)$ & $0(0)$ \\
Fisher exact test & & & $P<0.001$ & & \\
\hline
\end{tabular}


Table 4. Comparison between RECAF negative and RECAF positive NHL cases as regards laboratory findings.

\begin{tabular}{lcccc}
\hline & & RECAF (cutoff) & & \\
\cline { 2 - 5 } & Negative & Positive & \multicolumn{2}{c}{ T-test } \\
\cline { 2 - 5 } & Mean \pm SD & Mean \pm SD & t & $P$ \\
Lymphocyt & $6.000 \pm 8.532$ & $4.100 \pm 5.459$ & 0.972 & 0.336 \\
HB & $12.050 \pm 1.255$ & $11.803 \pm 1.068$ & 0.752 & 0.456 \\
Platelet & $273.650 \pm 91.468$ & $269.516 \pm 85.281$ & 0.164 & 0.870 \\
LDH & $597.000 \pm 143.546$ & $503.903 \pm 188.375$ & 1.883 & 0.066 \\
Age & $47.900 \pm 10.959$ & $48.194 \pm 11.626$ & -0.090 & 0.929 \\
\hline
\end{tabular}

Abbreviations: $\mathrm{Hb}$, hemoglobin; $\mathrm{LDH}$, lactate dehydrogenase; $\mathrm{SD}$, standard deviation.

the incorporation of AFP by MCF-7 human breast cancer cells $[11,14,21]$. Then, the same research group proved the existence of a specific membrane receptor for AFP on the surface of MCF-7 human breast cancer cells [22].

AFP serves as a growth factor in certain cancers, such as hepatocellular carcinomas, to enhance their growth and progression. Immunohistological detection of its receptor (RECAF) has been performed on a variety of tumors, including murine mammary tumors and human adenocarcinoma, human breast, colon, lung, rectal carcinoma, human breast cancer adenocarcinoma, hepatoma, and breast MCF-7 adenoand ductal carcinoma, breast metastasis [14, 22-26]. AFP is thought to regulate neoplastic growth via the presence of its receptor. Following the binding of AFP to its cell surface receptor (RECAF), it undergoes internalization via a receptor-mediated endocytosis process.

As the uptake of AFP and, hence, the expression of RECAF is related to the degree of cell maturation, immature or malignant cells re-express RECAF, while mature adult tissues lack RECAF expression [5]. In parallel, poorly differentiated normal cells, such as stem cells and reproductive cells, can express RECAF, which may explain the few positive cells observed in the NC group in our study. Also in our study, ALL cases showed the highest level of RECAF positive cells (32-40\%) in the PC group. This may be related to the degree of cell maturation, as blast cells are extremely immature. Moreover, negative RECAF cells were observed in patients suffering from diseases that arise from either partially differentiated cells, as in CML, end-stage cells, such as myeloma (plasma) cells, or primitive, but not embryonic cells, as in yolk sac tumors.

Furthermore, in our study, the expression of RECAF was variable among the different subtypes of NHL, with the highest percentage seen in FL and DLBCL $(P=0.001)$. From the results mentioned above; it is evident that the well-known heterogeneity of B-NHL disorders extends to their cellular expression of RECAF. Our results document for the first time the clear distinction between leukemic (DLBCL: FL and MCL) and non-leukemic lymphomas (CLL/SLL and MCL) via RECAF detection. Interestingly, none of HCL cases expressed RECAF. The negativity among all cases of HCL is in itself a positive finding that warrants further confirmatory studies.

No previous studies have investigated the unique pattern of RECAF expression in the different subtypes of lymphoma. However, we believe that RECAF may help in differentiating between different subtypes of lymphoma and in the detection of MRD and relapse. Moreover, RECAF may be a target of treatment in different types of LPD. Further studies are needed to confirm this.

Because detection of BM infiltration is essential in staging LPD patients, we investigated the possible role of RECAF expression in detecting $\mathrm{BM}$ infiltration, in comparison to routine histopathology. We found that in FL, MCL, and DLBCL patients, detection of RECAF via IHC was more sensitive than routine histopathology for BM infiltration detection $(P=0.01)$. In contrast, this was not observed in CLL and HCL patients. The added value provided by RECAF detection is the advantage of discriminating malignant from non-malignant lymphocyte populations and not merely assigning the lineage of the lymphoid population. Furthermore, RECAF as a single marker may be easier to perform instead of the full routine IHC panel in the cases already diagnosed via lymph node biopsy when clinicians just need to confirm the stage. Further comparative studies are needed to support our results.

As RECAF serves as a universal tumor marker, ongoing studies are investigating its use for targeting tumor cells [27]. Since AFP from one species binds to or is uptaken by cells from another species, the cross-reaction of anti-human AFP receptor mabs is a fortunate circumstance that allows the development of simple tumor-targeting experimental models in animals. The interaction between anti-AFP receptor antibodies and malignant cells is not limited to a passive binding but also modulates the rate of cell replication [5].

Furthermore, RECAF may be used for screening tumors in the future. Another study showed that a RECAF-based serum immunoassay can discriminate breast cancers from normal subjects or benign breast diseases with high sensitivity and specificity. The most valuable finding in this study is that the assay can detect the early stages of breast cancer with high sensitivity and specificity [5].

RECAF is significantly expressed in the bone marrow of 
patients with NHL/CLL. Its unique expression pattern may be a promising tool for the diagnosis of different subtypes of NHL. Furthermore, it may help in the detection of BM infiltration in lymphoma cells. This may be the basis for new target therapy for NHL based on RECAF expression. Further studies are needed to confirm this.

\section{Authors' Disclosures of Potential Conflicts of Interest}

No potential conflicts of interest relevant to this article were reported.

\section{REFERENCES}

1. Swerdlow SH, Campo E, Pileri SA, et al. The 2016 revision of the World Health Organization classification of lymphoid neoplasms. Blood 2016;12:2375-90.

2. Park Y, Park BB, Jeong JY, et al. Assessment of bone marrow involvement in patients with lymphoma: report on a consensus meeting of the Korean Society of Hematology Lymphoma Working Party. Korean J Intern Med 2016;31:1030-41.

3. Alpert E, Feller ER. Alpha-fetoprotein (AFP) in benign liver disease. Evidence that normal liver regeneration does not induce AFP synthesis. Gastroenterology 1978;74(5 Pt 1):856-8.

4. Deutsch HF. Chemistry and biology of alpha-fetoprotein. Adv Cancer Res 1991;56:253-312.

5. Moro R, Gulyaeva-Tcherkassova J, Stieber P. Increased alphafetoprotein receptor in the serum of patients with early-stage breast cancer. Curr Oncol 2012;19:e1-8.

6. Geuskens M, Naval J, Uriel J. Ultrastructural studies of the intracellular translocation of endocytosed alpha-foetoprotein (AFP) by cytochemistry and of the uptake of $3 \mathrm{H}$-arachidonic acid bound to AFP by autoradiography in rat rhabdomyosarcoma cells. J Cell Physiol 1986;128:389-96.

7. Uriel J, Naval J, Laborda J. alpha-Fetoprotein-mediated transfer of arachidonic acid into cultured cloned cells derived from a rat rhabdomyosarcoma. J Biol Chem 1987;262:3579-85.

8. Hajeri-Germond M, Naval J, Trojan J, Uriel J. The uptake of alpha-foetoprotein by C-1300 mouse neuroblastoma cells. Br J Cancer 1985;51:791-7.

9. Moro R, Fielitz W, Esteves A, Grunberg J, Uriel J. In vivo uptake of heterologous alphafetoprotein and serum albumin by ependymal cells of developing chick embryos. Int J Dev Neurosci 1984;2:143-8.

10. Moro R, Heuguerot C, Vercelli-Retta J, Fielitz W, López JJ, Roca $\mathrm{R}$. The use of radioiodinated alpha-fetoprotein for the scintigraphic detection of mouse mammary carcinomas. Nucl Med Commun 1984;5:5-12.

11. Uriel J, Poupon MF, Geuskens M. Alphafoetoprotein uptake by cloned cell lines derived from a nickel-induced rat rhabdomyosarcoma. Br J Cancer 1983;48:261-9.
12. Uriel J, Villacampa MJ, Moro R, Naval J, Failly-Crépin C. Uptake of radiolabeled alpha-fetoprotein by mouse mammary carcinomas and its usefulness in tumor scintigraphy. Cancer Res 1984;44:5314-9.

13. Naval J, Villacampa MJ, Goguel AF, Uriel J. Cell-type-specific receptors for alpha-fetoprotein in a mouse T-lymphoma cell line. Proc Natl Acad Sci U S A 1985;82:3301-5.

14. Villacampa MJ, Moro R, Naval J, Failly-Crepin C, Lampreave F, Uriel J. Alpha-fetoprotein receptors in a human breast cancer cell line. Biochem Biophys Res Commun 1984;122:1322-7.

15. Mizejewski GJ. Biological role of alpha-fetoprotein in cancer: prospects for anticancer therapy. Expert Rev Anticancer Ther 2002;2:709-35.

16. Benno RW, Williams TH. Evidence for intracellular localization of alpha-fetoprotein in the developing rat brain. Brain Res 1978;142:182-6.

17. Moro R, Uriel J. Early localization of alpha-fetoprotein in the developing nervous system of the chicken. Oncodev Biol Med 1981;2:391-8.

18. Uriel J, Trojan J, Dubouch P, Pineiro A. Intracellular alphafetoprotein and albumin in the developing nervous system of the baboon. Pathol Biol (Paris) 1982;30:79-83.

19. Toran-Allerand CD. Coexistence of alpha-fetoprotein, albumin and transferrin immunoreactivity in neurones of the developing mouse brain. Nature 1980;286:733-5.

20. Trojan J, Uriel J. Immunocytochemical localisation of alphafetoprotein (AFP) and serum albumin (ALB) in ecto-, meso- and endodermal tissue derivatives of the developing rat. Oncodev Biol Med 1982;3:13-22.

21. Lorenzo HC, Geuskens M, Macho A, et al. Alpha-fetoprotein binding and uptake by primary cultures of human skeletal muscle. Tumour Biol 1996;17:251-60.

22. Uriel J, Failly-Crepin C, Villacampa MJ, Pineiro A, Geuskens M. Incorporation of alphafetoprotein by the MCF-7 human breast cancer cell line. Tumour Biol 1984;5:41-51.

23. Moro R, Tamaoki T, Wegmann TG, Longenecker BM, Laderoute MP. Monoclonal antibodies directed against a widespread oncofetal antigen: the alpha-fetoprotein receptor. Tumour Biol 1993;14:116-30.

24. Laderoute M, Willans D, Wegmann T, Longenecker M. The identification, isolation and characterization of a 67 kilodalton, PNA-reactive autoantigen commonly expressed in human adenocarcinomas. Anticancer Res 1994;14:1233-45.

25. Alava MA, Iturralde M, Lampreave F, Piñeiro A. Specific uptake of alpha-fetoprotein and albumin by rat Morris 7777 hepatoma cells. Tumour Biol 1999;20:52-64.

26. Mizejewski GJ, Mirowski M, Garnuszek P, et al. Targeted delivery of anti-cancer growth inhibitory peptides derived from human alpha-fetoprotein: review of an International Multi-Center Collaborative Study. J Drug Target 2010;18:575-88.

27. Pak VN. Selective targeting of myeloid-derived suppressor cells in cancer patients through AFP-binding receptors. Future Sci OA 2018;5:FSO321. 